\title{
Dearomative Michael addition involving enals and 2- nitrobenzofurans realized under NHC-catalysis
}

\author{
Mateusz Dyguda, ${ }^{\mathrm{a}, \$}$ Anna Skrzyńska, ${ }^{\mathrm{a}, \downarrow}, *$ Lesław Sieroń, ${ }^{\mathrm{b}}$ Łukasz Albrecht $^{\mathrm{a}, *}$
}

In the manuscript the first enantioselective dearomative Michael addition between $\alpha, \beta$-unsaturated aldehydes and 2nitrobenzofurans realized under $\boldsymbol{N}$-heterocyclic carbene activation has been described. The reaction proceeds via addition of homoenolate to Michael acceptors leading to the formation of biologically important heterocycles with high yields and stereoselectivities. Their functionalization potential has been confirmed in selected, diastereoselective transformations.

The discovery of new synthetic approaches that allows for the transformation of aromatic systems in a highly selective fashion remains an exciting area of research. ${ }^{1}$ As a consequence reactions capable of disturbing the aromatic $\pi$-system receive considerable attention. Among different approaches to accomplish this task, catalytic asymmetric dearomatization (CADA) reactions of simple (hetero)aromatic compounds constitute a highly reliable tool for the assembly of enantiomerically enriched polycyclic molecules. ${ }^{2}$ Many of these reactions are typically focused on the process of dearomatization of electron-rich (hetero)arenes based on their nucleophilic nature. ${ }^{3}$ Introduction of an appropriate electronwithdrawing substituents in the structure of (hetero)arenes leads to reversal of their reactivity into electron-deficient systems acting as electrophile susceptible to CADA. ${ }^{4}$

Recently, the important applications of electron-poor nitrosubstituted heteroarenes (such as 2- and 3-nitroindoles, ${ }^{5}$ 2nitrobenzofurans $s^{6,7}$ or 2- and 3-nitrobenzothiophenes ${ }^{8}$ ) in dearomative transformations for the construction of fusedheterocycles appeared in the literature. Due to the immense biological importance of 2,3-disubstituted-2,3dihydrobenzoheterocycles motif, ${ }^{9}$ the development of new strategies for the construction of such chiral oxygen- or sulfurcontaining scaffolds receives considerable attention from the organic and medicinal chemistry community. In recent years, 2nitobenzofurans and 2-nitrobenzothiophenes have been successfully used as C-2 synthons in various enantioselective dearomative reactions using both transition-metal catalysis $^{6,8 a, 8 b}$ and organocatalysis. ${ }^{7,8 c}$ However, all of these

a. Institute of Organic Chemistry, Faculty of Chemistry, Lodz University of Technology Żeromskiego 116, 90-924 Łódź, Poland.

b. Institute of General and Ecological Chemistry, Faculty of Chemistry, Lodz University of Technology, Żeromskiego 116, tódź, 90-924, Poland.

E-mail: lukasz.albrecht@p.lodz.pl; anna.skrzynska@p.lodz.pl; web: http://www.ateamlab.p.lodz.pl/

Electronic Supplementary Information (ESI) available: [details of any supplementary information available should be included here]. See DOI: 10.1039/x0xx00000x.

‡ These authors contributed equally. transformations proceed in a cascade manner and utilize both the electrophilicity of the starting material and nucleophilicity of the initially formed adduct, thus leading to the polycyclic frameworks, mainly $(3+2)$ - or $(4+2)$-cycloadducts (Scheme 1, top). ${ }^{6-8}$ On the other hand, 2-nitrobenzofurans, as a class of promising reagents that undergo simple dearomative Michael additions (Scheme 1, top) with such an approach being still undeveloped. A survey of the literature revealed only one example of this type of reactivity. In 2019 Yuan group described the enantioselective reaction of 2-nitrobenzofurans with 3pyrrolyl-oxindoles in the straightforward construction of chiral 2,3-dihydrobenzofurans (Scheme 1, center). ${ }^{10}$

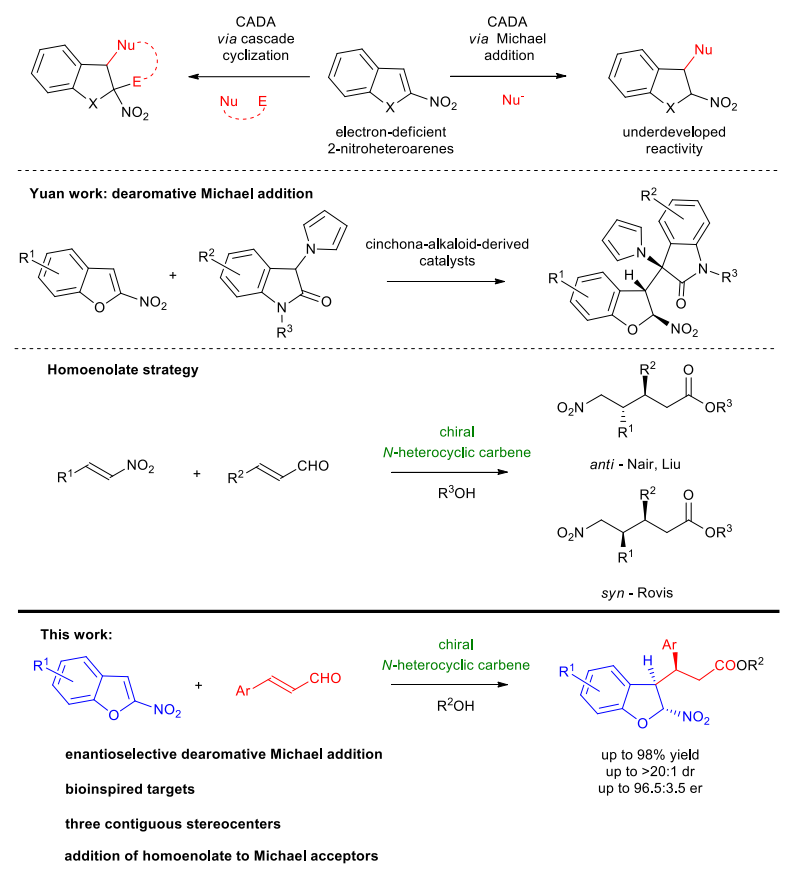

Scheme 1. Design of catalytic asymmetric dearomative reactions of 2-nitrobenzoheteroarenes.

Given the lack of simple additions involving 2-nitrobenzofurans and our continuous research activity in catalytic asymmetric dearomative transformations, ${ }^{11}$ we became interested in the development of the enantioselective CADA Michael reaction between electron-deficient 2-nitroheteroarenes $\mathbf{1}$ and $\alpha, \beta$ unsaturated aldehydes 2 . Herein, we report the first organocatalytic dearomative Michael addition realized under NHC catalysis ${ }^{12}$ leading to the formation of chiral 2,3disubstituted-2,3-dihydrobenzo-heterocycles 3 (Scheme 1, bottom). The reaction was realized employing homoenolate chemistry that served as a powerful means for the redox 
functionalization of $\alpha, \beta$-unsaturated aldehydes with nitroolefins constituting an important class of electrophiles employed (Scheme 1, center). ${ }^{13}$

The reaction between 2-nitrobenofuran $1 \mathrm{a}$ and transcinnamaldehyde $\mathbf{2 a}$ was selected as a model transformation (Table 1). Initially, various readily available chiral NHC catalysts $\mathbf{4}$ were evaluated in THF at room temperature. It was found that 2-nitrobenzofuran 1a was fully consumed when the reactions were carried out in the presence of the precatalysts $\mathbf{4 a , b}, \mathbf{d}$ using $\mathrm{Cs}_{2} \mathrm{CO}_{3}$ as a base, but 3a was isolated with moderate yields (Table 1, entries 1-2, 4). Aminoindanol-based NHC precatalyst 4c bearing a pentafluorophenyl group showed no catalytic

Table 1. NHC-catalyzed dearomative Michael addition with enals and 2-nitrobenzofurans - optimization studies. ${ }^{a}$

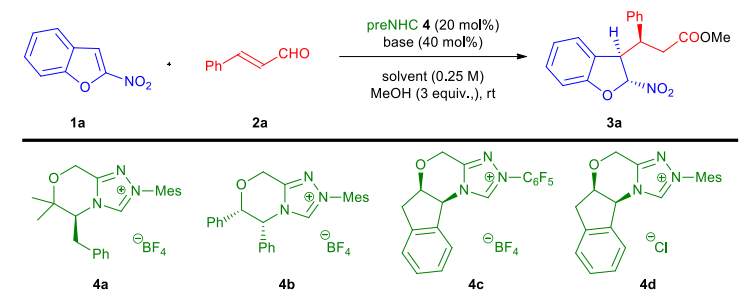

\begin{tabular}{|c|c|c|c|c|c|}
\hline & $\begin{array}{c}\text { Solvent } \\
\text { (preNHC) }\end{array}$ & Base & $\begin{array}{c}\text { Conv. } \\
\text { (yield) }[\%]^{\mathrm{b}}\end{array}$ & $d r^{c}$ & $e r^{d}$ \\
\hline 1 & THF (4a) & $\mathrm{Cs}_{2} \mathrm{CO}_{3}$ & $>95(60)$ & $>20: 1$ & $90: 10$ \\
\hline 2 & THF (4b) & $\mathrm{Cs}_{2} \mathrm{CO}_{3}$ & $>95$ (62) & $>20: 1$ & $15: 85$ \\
\hline 3 & THF (4c) & $\mathrm{Cs}_{2} \mathrm{CO}_{3}$ & $<5$ & n.d & n.d \\
\hline 4 & THF (4d) & $\mathrm{Cs}_{2} \mathrm{CO}_{3}$ & $>95(66)$ & $>20: 1$ & 92.8 \\
\hline 5 & $\operatorname{THF}(\mathbf{4 d})$ & $\mathrm{K}_{2} \mathrm{CO}_{3}$ & $>95(60)$ & $>20: 1$ & $90: 10$ \\
\hline 6 & THF (4d) & DIPEA & $>95$ (54) & $>20: 1$ & $92: 8$ \\
\hline 7 & THF (4d) & TEA & $>95(60)$ & $9: 1$ & $92: 8$ \\
\hline 8 & DCE $(\mathbf{4 d})$ & $\mathrm{Cs}_{2} \mathrm{CO}_{3}$ & $<5$ & n.d & n.d \\
\hline 9 & 1,4-Dioxane (4d) & $\mathrm{Cs}_{2} \mathrm{CO}_{3}$ & $<5$ & n.d & n.d \\
\hline 10 & $\mathrm{Et}_{2} \mathrm{O}(\mathbf{4 d})$ & $\mathrm{Cs}_{2} \mathrm{CO}_{3}$ & $>95(43)$ & $>20: 1$ & $97: 3$ \\
\hline 11 & $\mathrm{Et}_{2} \mathrm{O}(\mathbf{4 d})$ & TEA & $>95(76)$ & $>20: 1$ & $96: 4$ \\
\hline $12^{e}$ & $\mathrm{Et}_{2} \mathrm{O}(\mathbf{4 d})$ & TEA & $>95(93)$ & $>20: 1$ & $96.5: 3.5$ \\
\hline $13^{f}$ & $\mathrm{Et}_{2} \mathrm{O}(\mathbf{4 d})$ & TEA & $>95(74)$ & $16: 1$ & $96: 4$ \\
\hline $14^{\mathrm{e}, \mathrm{g}}$ & $\mathrm{Et}_{2} \mathrm{O}(\mathbf{4 d})$ & TEA & >95 (92) & $>20: 1$ & $96.5: 3.5$ \\
\hline $15^{e, h}$ & $\mathrm{Et}_{2} \mathrm{O}(\mathbf{4 d})$ & TEA & $>95(74)$ & $>20: 1$ & $96.5: 3.5$ \\
\hline $16^{e, h, i}$ & $\mathrm{Et}_{2} \mathrm{O}(\mathbf{4 d})$ & TEA & $>95(84)$ & $>20: 1$ & $96.5: 3.5$ \\
\hline
\end{tabular}

a Reactions performed on a $0.05 \mathrm{mmol}$ scale using 1a (1.0 equiv.), 2a (1.5 equiv.) and the preNHC catalyst $4(20 \mathrm{~mol} \%)$ in $0.2 \mathrm{~mL}$ of the solvent for $24 \mathrm{~h}$ at rt. ${ }^{b}$ Determined by ${ }^{1} \mathrm{H}$ NMR of crude reaction mixture. In parenthesis yield of isolated product 3a after column chromatography is given. ${ }^{\mathrm{c}}$ Determined by ${ }^{1} \mathrm{H}$ NMR of crude reaction mixture. ${ }^{d}$ Determined by chiral HPLC. ${ }^{e}$ The reaction performed at $5{ }^{\circ} \mathrm{C}$. ${ }^{\mathrm{f}}$ The reaction performed at $-10{ }^{\circ} \mathrm{C}$. $\mathrm{g}$ The reaction performed using $4 \mathrm{~d}$ (10 mol\%). ${ }^{\text {h }}$ The reaction performed using $4 \mathbf{d}$ (5 mol\%). ' Reaction performed on a 1 $\mathrm{mmol}$ scale for $48 \mathrm{~h}$. DCE - 1,2-dichloroethane.

activity in the reaction (Table 1, entry 3). Careful examination of ${ }^{1} \mathrm{H}$ NMR of crude reaction mixtures indicated that methyl 3phenylpropanoate was the by-product responsible for low yields observed. Screening of bases did not lead to significant improvement of results. However, both $\mathrm{Cs}_{2} \mathrm{CO}_{3}$ and triethylamine provided the best reaction outcomes (Table 1 , compare entries 4,7 vs. 5, 6). Subsequently, solvent screening revealed that diethyl ether was the best choice, yielding the desired product $3 a$ without erosion of enantio- or diastereoselectivity, when reacting with TEA as base and $\mathbf{4 d}$ as a NHC-precatalyst (Table 1, compare entry 11 vs. 7-10). Lowering the reaction temperature to $5{ }^{\circ} \mathrm{C}$ led to a substantial increase of the yield with an excellent enantiomeric excess (Table 1, entry 12). It should be noted that under these conditions the formation of methyl 3-phenylpropanoate was not observed in the crude reaction mixture. The decrease of the temperature to $-10^{\circ} \mathrm{C}$ led to the drop of the diastereoselectivity of the process (Table 1 , entry 13 ). When the catalyst loading $\mathbf{4 d}$ was reduced (to $10 \mathrm{~mol} \%$ ) the addition still proceeded smoothly (Table, entry 14). Unfortunately, further reduction of the amount of catalyst (to $5 \mathrm{~mol} \%$ ) suppressed the reaction rate resulting in lower yield (Table 1 , entry 15). Finally, the conditions shown in Table 1 , entry 14 were selected as the optimal conditions to investigate the generality of the process. Importantly, the reaction proved to be easily scalable with comparable results obtained on a 20 -fold higher scale using only 5 mol\% of the precatalyst $4 \mathbf{d}$ (Table 1 , entry 16 ).

Under the optimized reaction conditions, the scope and limitations of the reaction was carefully explored (Schemes 2 and 3). As shown in Scheme 2, the dearomative Michael reaction was applicable to a wide range of $\alpha, \beta$-unsaturated

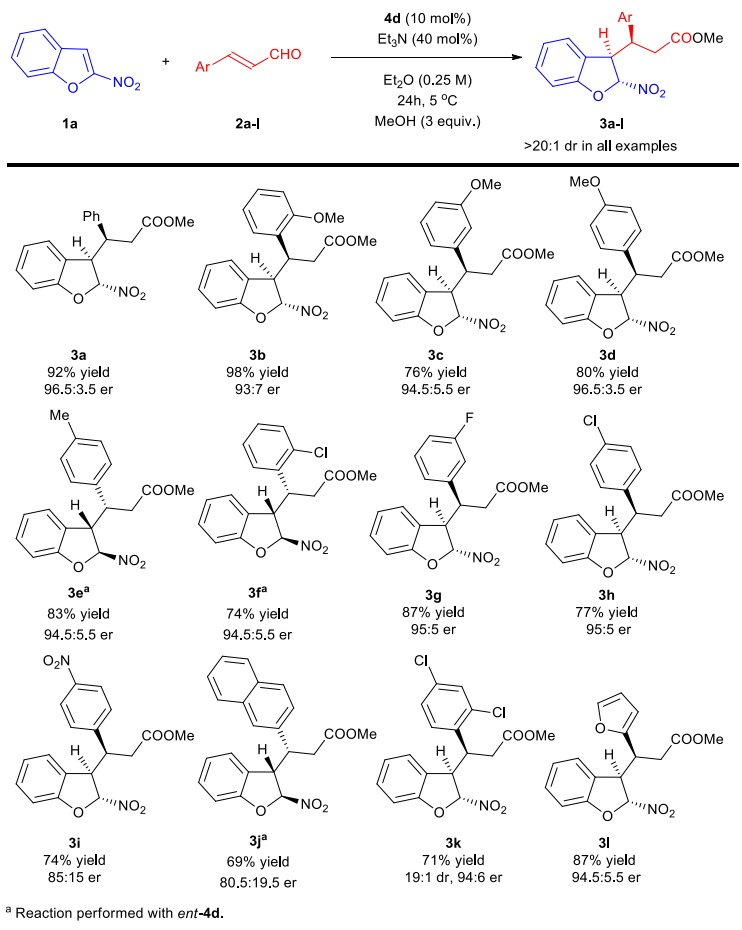

Scheme 2. NHC-catalyzed dearomative Michael addition with enals and 2nitrobenzofurans - $\alpha, \beta$-unsaturated aldehyde 2 scope. ${ }^{\text {a }}$

aldehydes $\mathbf{2 a - 1}$, affording corresponding products $\mathbf{3 a - I}$ in high yields and high diastereo- and enantioselectivity. It was found that the reactivity and stereoselectivity were almost unaffected by the incorporation of various electron-donating substituents at different positions of the aromatic ring in transcinnamaldehydes $\mathbf{2 b}$-e (Scheme 2, products $\mathbf{3 b} \mathbf{b}-\mathbf{e}$ ). Aldehydes 2f-h with electron-withdrawing substituents in different positions (2-Cl, 3-F and 4-Cl) on the aromatic ring were also all suitable substrates for this reaction, resulting in the formation 
of corresponding products $\mathbf{3} \mathbf{f}-\mathbf{h}$ in high yield and stereoselectivity. Notably, in the case of aldehyde $\mathbf{2} \mathbf{i}$, the reaction proceeded smoothly with 2-nitrobenzofuran $1 \mathbf{1 a}$, but the desired product $\mathbf{3 i}$ was obtained with diminished enantiocontrol. Also trans-cinnamldehydes $\mathbf{2 j}$ and $\mathbf{2 k}$ with double substitution pattern gave access to the corresponding products $\mathbf{3} \mathbf{j}$ and $\mathbf{3 k}$ in moderate to high enantioselectivity. Finally, the reactivity and stereoselectivity were hardly affected by the incorporation of heteroaromatic ring in $\mathbf{2} \mathbf{l}$, as $\mathbf{3} \mathbf{l}$ was obtained effectively. Further exploration of the substrate scope was focused on the utilization of various 2-nitrobenzofurans 1be (Scheme 3). The dearomative Michael reaction was compatible with C5-substituted acceptors 1 containing groups of different electronic properties, providing products $3 \mathbf{m}-\mathbf{p}$ in good to high yields and with excellent stereoselection.

Finally, different alcohols, such as ethanol, butanol and sterically hindered tert-butanol were tested. To our delight, ethanol worked well to give the $\mathbf{3 q}$ in high yield with excellent enantiomeric ratio. Attempts to use other alcohols resulted in suppression of reactivity ( $<5 \%$ conversion, products not shown). Similarly, when 2-nitrobenzothiophene was used, no reaction was observed.

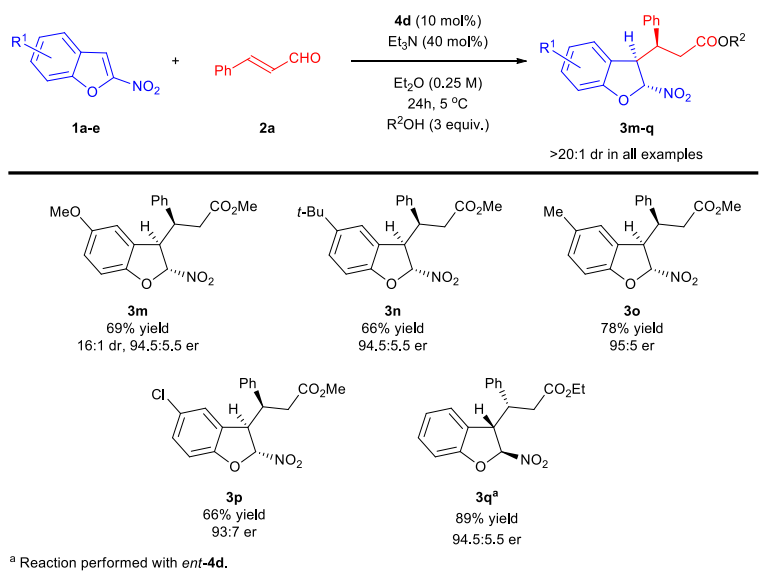

Scheme 3. NHC-catalyzed dearomative Michael addition with enals and 2nitrobenzofurans - 2-nitrobenzofuran 1 scope. ${ }^{\text {a }}$

The usefulness of the obtained adducts was demonstrated in selected transformations (Scheme 4). Firstly, the treatment of the optically pure adduct 3a with diisobutylaluminum hydride in THF led to chemoselective reduction of the ester group to give an alcohol $\mathbf{5}$ in $68 \%$ yield without erosion of diastereoselectivity (Scheme 4, eq. 1). Product 3a was also transformed into the $\delta$-lactam 6 via a cascade reaction with sodium borohydride in the presence of nickel chloride in $\mathrm{MeOH}$. Initially, the reduction of the nitro group and lactonization occurred. Subsequently, the reaction involving opening of the dihydrobenzofuran ring and reduction provided 6 as single diastereoisomer (Scheme 4, eq. 2).

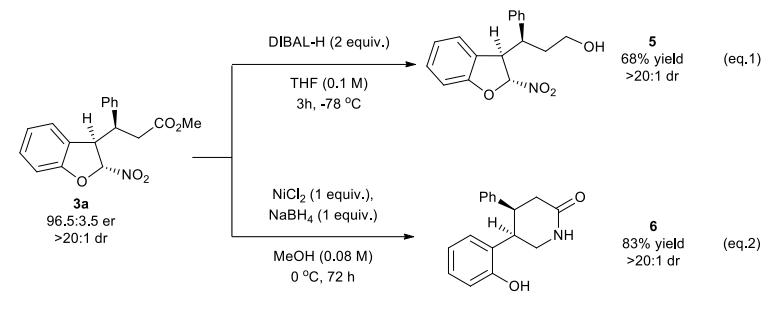

Scheme 4. Diastereoslective transformations of 3a.

The absolute configuration of the products was unequivocally confirmed by the single crystal X-ray analysis of the $\mathbf{3 j}$ (for details, see Supporting Information). ${ }^{14}$ The stereochemistry of other products was assigned by analogy. Based on the configurational assignments, a possible mechanism of this dearomative Michael reaction was proposed (Scheme 5). It was initiated through the addition of an in situ generated NHC 7 to the $\alpha, \beta$-unsaturated aldehyde $\mathbf{2 a}$ to give the corresponding Breslow intermediate 8. The Michael acceptor 1a was activated and oriented in space through the $\mathrm{H}$-bonding interaction between the hydroxyl group of $\mathbf{8}$ and the nitro group in $\mathbf{1 a}$. Simultaneously, $\pi$-stacking between the phenyl ring of $\mathbf{8}$ and aromatic ring of 1a and steric effect of chiral motif of the NHC catalyst favored the Re-face attack of C3-position of 2nitrobenzofuran by homoenolate $\mathbf{8}$ in stereoselective manner. With the formation of adduct $\mathbf{9}$ accomplished, its protonation and subsequent tautomerization to acyl azolium 10 took place. The esterification of $\mathbf{9}$ in the presence of nucleophile furnished the final adduct $3 a$ with $(\mathrm{C} 2 R, \mathrm{C} 3 R, \mathrm{C} 10 S)$ configuration.

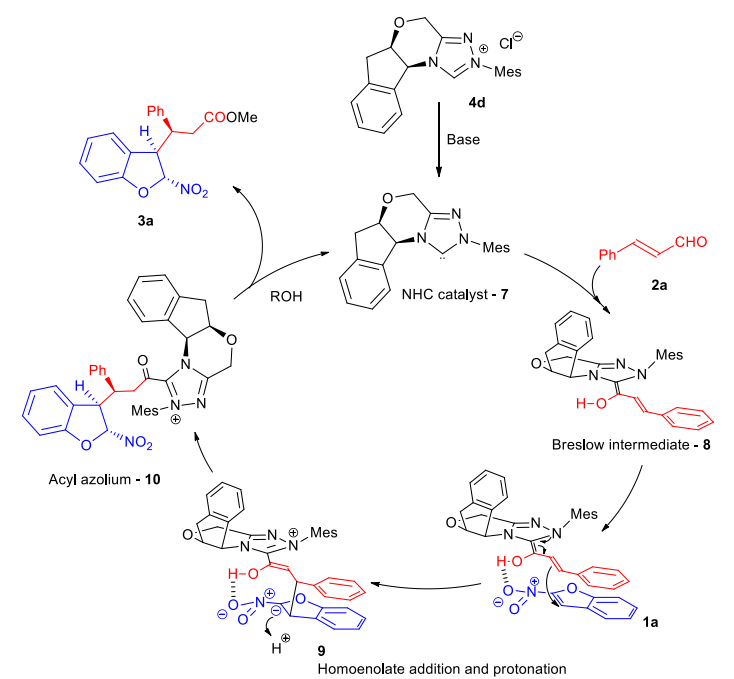

Scheme 5. NHC-catalyzed dearomative Michael addition with enals and 2nitrobenzofurans - mechanistic considerations.

In summary, we have successfully developed the first catalytic asymmetric dearomative transformation between 2nitrobenzofurans and $\alpha, \beta$-unsaturated aldehydes catalyzed by $N$-heterocyclic carbenes. This process proceeds through the addition of a homoenolate to 2-nitrobenzofurans leading to enantioenriched heterocycles with three contiguous stereocenters with high efficiency and stereoselectivity. The presented work constitutes the unique application of NHC catalysis in the transformation of electron-poor 2- 
nitrobenzofurans. Further exploration on the catalytic asymmetric dearomatization of electron-deficient heteroarenes is currently underway.

This project was realized within the Własny Fundusz Stypendialny programme (RNN/WFS/9/2021) funds from Lodz University of Technology. This contribution has been completed while the first author (MD) was the Doctoral Candidate in the Interdisciplinary Doctoral School of Lodz University of Technology, Poland.

\section{Conflicts of interest}

There are no conflicts to declare.

\section{Notes and references}

1 For selected reviews, see: (a) A. R. Pape, Kaliappan and E. P. Kündig, Chem. Rev., 2000, 100, 2917-2940; (b) F. L. Ortiz, M. L. Iglesias, I. Fernández, C. M. A. Sánchez and G. R. Gómez, Chem. Rev., 2007, 107, 1580-1691; (c) S. Quideau, L. Pouységu, and D. Deffieux, Synlett 2008, 467-495; (d) S. P. Roche, and J. A. Porco Jr, Angew. Chem., Int. Ed. 2011, 50, 4068-4093; (e) Q. Ding, X. Zhou, and R. Fan, Org. Biomol. Chem. 2014, 12, 4807-4815; (f) W. C. Wertjes, E. C. Southgate, and D. Sarlah, Chem. Soc. Rev. 2018, 47, 7996-8017.

2 For a book, see: (a) S.-L. You, Wiley-VCH, Weinheim, 2016. For selected reviews, see: (b) C.-X. Zhuo, W. Zhang and S.-L. You, Angew. Chem., Int. Ed. 2012, 51, 12662-12686; (c) J. A. Bull, J. J. Mousseau, G. Pelletier and A. B. Charette, Chem. Rev. 2012, 112, 2642-2713; (d) C.-X. Zhuo, C. Zheng and S.-L. You, Acc. Chem. Res. 2014, 47, 2558-2573; (e) Z.-P. Yang, Q.-F. Wu, W. Shang and S.-L. You, J. Am. Chem. Soc. 2015, 137, 1589915906; (f) C. Zheng and S.-L. You, Chem 2016, 1, 830-857; (g) W.-T. Wu, L. Zhang and S.-L. You, Chem. Soc. Rev. 2016, 45 1570-1580; (h) C. Zheng and S.-L. You, Nat. Prod. Rep. 2019, 36, 1589-1605; (i) J. An and M. Bandini, Eur. J. Org. Chem. 2020, 4087-4097; (j) C. Zheng and S.-L. You, ACS Cent. Si. 2021, 7, 432-444; (k) B. Baire and V. Nair, Asian J. Org. Chem. 2021, 10, $932-948$

3 For selected reviews, see: (a) J. Nan, Z. Zuo, L. Luo, L. Bai, H. Zheng, Y. Yuan, J. Liu, X. Luan and Y. Wang, J. Am. Chem. Soc. 2013, 135, 17306-17309. For recently examples, see: (b) Z.-P. Yang, R. Jiang, C. Zheng and S.-L. You, J. Am. Chem. Soc. 2018, 140, 3114-3119; (c) P. Wang, J. Wang, L. Wang, D. Li, K. Wang, Y. Liu, H. Zhu, X. Liu, D. Yang and R. Wang, Adv. Synth. Catal. 2018, 360, 401-405; (d) X. Liu, J. Zhang, L. Bai, L. Wang, D. Yang and R. Wang, Chem. Sci. 2020, 11, 671-676; (e) M.-L. Han, W. Huang, Y.-W. Liu, M. Liu, H. Xu, H. Xiong and H.-X. Dai, Org. Lett. 2021, 23, 172-177.

4 For selected examples, see: (a) I. Chataigner and S. R. Piettre, Org. Lett. 2007, 9, 4159-4162; (b) S. Lee, I. Chataigner and R. S. Piettre, Angew. Chem., Int. Ed. 2010, 50, 472-476; (c) B. M. Trost, V. Ehmke, B. M. O'Keefe and D. A. Bringley, J. Am. Chem. Soc. 2014, 136, 8213-8216.

5 For the selected examples about the application of nitroindoles in asymmetric reactions, see: (a) Y. Li, F. Tur, R. P. Nielsen, H. Jiang, F. Jensen and K. A. Jørgensen, Angew. Chem., Int. Ed. 2016, 55, 1020-1024; (b) D.-F. Yue, J.-Q. Zhao, X.-Z. Chen, Y. Zhou, X.-M. Zhang, X. Y. Xu and W.-C. Yuan, Org. Lett. 2017, 19, 4508-4511; (c) J.-Q. Zhao, X.-J. Zhou, Y.-Z. Chen, X.-Y. Xu, X.-M. Zhang and W.-C. Yuan, Adv. Synth. Catal. 2018 360, 2482-2487; (d) H.-M. Wang, J.-Y. Zhang, Y.-S. Tu and J.-L. Zhang, Angew. Chem., Int. Ed. 2019, 58, 5422-5426; (e) K.-Z. Li, T. P. Goncalves, K.-W. Huang and Y. Lu, Angew. Chem., Int Ed. 2019, 58, 5427-5431.

6 For the selected examples about the application of nitrobenzofuranes in transition-metal catalysis, see: (a) J.-Q. Zhao, X.-J. Zhou, Y. Zhou, X.-Y. Xu, X.-M. Zhang and W.-C. Yuan,
Org. Lett. 2018, 20, 909-912; (b) Q. Cheng, H.-J. Zhang, W.-J. Yue and S.-L. Yo, Chem 2017, 3, 428-436.

7 For the selected examples about the application of nitrobenzofurans in organocatalytic reactions, see: (a) D. Janssen-Müller, M. Fleige, D. Schlüns, M. Wollenburg, C. G. Daniliuc, J. Neugebauer and F. Glorius, ACS Catal. 2016, 6, 5735-5739; (b) J.-Q. Zhao, F. Y. Yang, X.-J. Zhou, Y. You, Z.-H. Wang, M.-Q. Zhou, X.-M. Zhang, X.-Y. Xu and W.-C. Yuan, Org. Lett. 2019, 21, 660-664; (c) X.-J. Zhou, J.-Q. Zhao, X.-M. Chen, J.-R. Zhuo, Y.-P. Zhang, Y.-Z. Chen, X.-M. Zhang, X.-Y. Xu and W.-C. Yuan, J. Org. Chem. 2019, 84, 4381-4391; (d) X.-H. Yang, J.-P. Li, D.-C. Wang, M.-S. Xie, G.-R. Qu and H.-M. Guo, Chem. Commun. 2019, 55, 9144-9147.

8 For the selected examples about the application of nitrobenzothiophenes in asymmetric reactions, see: (a) $\mathrm{Q}$. Cheng, F. Zhang, Y. Cai, Y.-L. Guo and S.-L. You, Angew. Chem., Int. Ed. 2018, 57, 2134-2138; (b) D.-F. Yue, J.-Q. Zhao, Y.-Z. Chen, X.-M. Zhang, X.-Y. Xu and W.-C. Yuan, Adv. Synth. Catal. 2018, 360, 1420-1425; (c) X.-M. Chen, C.-W. Lei, D.-F. Yue, J.Q. Zhao, Z.-H. Wang, X.-M. Zhang, X.-Y. Xu and W.-C. Yuan, Org. Lett. 2019, 21, 5452-5456.

9 For selected review, see: (a) Z. Chen, M. Pitchakuntla and Y. Jia, Nat. Prod. Rep. 2019, 36, 666-690. For selected examples, see: (b) T. Furuya and A. Ikuta, Chem. Pharm. Bull. 1968, 16, 771; (c) T. Hayashi and R. H. Thomson, Phytochemistry 1975, 14, 1085-1087; (d) Y. Mimaki, A. Kameyama, Y. Sashida, Y. Miyata and A. Fujii, Chem. Pharm. Bull. 1995, 43, 893-895.

10 Z.-Z. Ge, L. Yang, Y. You, Z.-H. Wang, K.-X. Xie, M.-Q. Zhou, J.Q. Zhao, W.-C. Yuan, Chem. Commun. 2020, 56, 2586-2589.

11 (a) A. Skrzyńska, A. Przydacz, Ł. Albrecht, Org. Lett. 2015, 17, 5682-5685; (b) X. Y. Gao, R. J. Yan, B. X. Xiao, W. Du, Ł. Albrecht and Y.-C. Chen, Org. Lett. 2019, 21, 9628-9632; (c) J. Bojanowski, A. Skrzyńska and A. Albrecht, Asian J. Org. Chem. 2019, 8, 844-848; (d) A. Przydacz, M. Dyguda, A. Topolska, A. Skrzyńska, C.-J. Xu, Y.-C. Chen and $Ł$. Albrecht, Org. Biomol. Chem. 2020, 18, 5816-5821; (e) A. Skrzyńska, S. Frankowski, A. Topolska, M. Dyguda, X.-Y. Gao, Ch.-J. Xu, Y.-C. Chen, and $Ł$. Albrecht, Chem. Commun. 2021, 57, 1667-1670; (f) M. Saktura, S. Frankowski, B. Joachim and $Ł$. Albrecht, Synthesis 2021, 53, 309-317; (g) M. Saktura, A. Skrzyńska, S. Frankowski, S. Wódka, Ł. Albrecht, Molecules 2021, 26, 4992-5002.

12 For a book, see: (a) A. T. Biju, Wiley-VCH, Weinheim, 2018. For selected reviews, see: (b) D. M. Flanigan, F. RomanovMichailidis, N. A. White and T. Rovis, Chem. Rev. 2015, 115, 9307-9387; (c) M. Zhao, Y.-T. Zhang, J. Chen and L. Zhou, Asian J. Org. Chem. 2018, 7, 54-69.

13 For selected reviews on homoenolate chemistry realized under NHC catalysis: (a) V. Nair, R. S. Menon, A. T. Biju, C. R. Sinu, R. R. Paul, A. Jose and A. Sreekumar, Chem. Soc. Rev. 2011, 40, 5336-5346; (b) R. S. Menon, A. T. Biju and V. Nair, Chem. Soc. Rev. 2015, 44, 5040-5052; (c) B. Maij, Asian J. Org. Chem. 2018, 7, 70-84. For examples involving nitroolefins as electrophiles, see: (d) V. Nair, C. R. Sinu, B. P. Babu, V. Varghese, A. Jose and E. Suresh, Org. Lett. 2009, 11, 55705573; (e) B. Maji, L. Ji, S. Wang, S. Vedachalam, R. Ganguly and X.-W. Liu, Angew. Chem., Int. Ed. 2012, 51, 8276-8280; (f) N. A. White, D. A. DiRocco and T. Rovis, J. Am. Chem. Soc. 2013, 135, 8504-8507.

14 CCDC 2105519 contains the supplementary crystallographic data for this paper. These data can be obtained free of charge from The Cambridge Crystallographic Data Centre via www.ccdc.cam.ac.uk/structures 